\title{
IDENTIFIKASI KANDUNGAN UNSUR LOGAM BATUAN MENGGUNAKAN METODE XRF (X-RAY FLOURESCENCE) (STUDI KASUS: KABUPATEN BUTON)
}

\author{
Jamaluddin $^{1 *}$, Emi Prasetyawati Umar ${ }^{2}$ \\ ${ }^{1}$ Geological Engineering, School of Geosciences, China University of Petroleum (East China), Qingdao, China. \\ ${ }^{2}$ Jurusan Teknik Pertambangan, Universitas Muslim Indonesia, Makassar, Indonesia. \\ *Penulis koresponden. Alamat email: jamaljamaluddin1994@gmail.com
}

\begin{abstract}
Abstrak
Tujuan dari penelitian ini adalah untuk menentukan konsentrasi unsur logam besi (Fe), Mangan $\mathrm{Mn}$ ), and nikel (Ni). Metode yang digunakan dalam penelitian ini yaitu dengan metode X-Ray (Fluoresence (XRF). Hasil penelitian menunjukkan bahwa konsentrasi rata-rata unsur logam besi (Fe) pada sampel Buton 1, Buton 2, Buton 3 dan Buton 4 berturut-turut adalah $48.17 \%, 49.49 \%, 56.64 \%$ dan $41.63 \%$. Mangan (Mn) $1.78 \%, 1.81 \%, 0.985 \%$ dan $1.69 \%$. Nikel (Ni) $3.34 \%, 3.18 \%, 9.22 \%$ dan $3.88 \%$. Dari hasil karakterisasi X-Ray Fluorenscence (XRF) didapatkan besi (Fe) dominan terkandung dalam sampel dengan konsentrasi sekitar $41.63 \%$ sampai $56.64 \%$. Bijih besi mengandung material magnetik berbasis besi ( $\mathrm{Fe})$ dalam bentuk mineral oksida besi yaitu Hematit $\left(\mathrm{Fe}_{2} \mathrm{O}_{3}\right)$.
\end{abstract}

Kata kunci: Buton, Hematit, Logam, X-Ray Flourescence (XRF).

\begin{abstract}
The aim of this research is determine the concentration of metallic elements iron $(\mathrm{Fe})$, manganese $(\mathrm{Mn})$, and nickel (Ni). The method used in this research is the method of X-ray fluorescence (XRF). The result of the research shown an average concentration of the metal element iron (Fe) at Buton 1, Buton 2, Buton 3 and Buton 4 samples respectively is $48.17 \%, 49.49 \%, 56.64 \%$ and $41.63 \%$. Mangan (Mn) $1.78 \%, 1.81 \%, 0.985 \%$ and $1.69 \%$. Nikel (Ni) $3.34 \%, 3.18 \%, 9.22 \%$ and $3.88 \%$. From the characterization of X-Ray Fluorenscence (XRF), the iron (Fe) were found in samples with concentrations of about $41.63 \%$ to $56.64 \%$. Iron ore - based magnetic material containing iron $(\mathrm{Fe})$ in mineral form of iron oxide that is hematite $\left(\mathrm{Fe}_{2} \mathrm{O}_{3}\right)$.
\end{abstract}

Key Words : Buton, Hematite, Metallic, X-Ray Flourescence (XRF).

\section{Pendahuluan}

Kepulauan Indonesia terletak di antara dua kontinen yaitu, kontinen Asia di bagian baratlaut dan kontinen Australia di bagian tenggara serta terletak antara dua samudera yaitu Samudera Pasifik dan Samudera Indonesia. Indonesia ditinjau dari titik pandang geodinamika kepulauan terletak dalam zona konvergen antara tiga lempeng yang saling bergerak satu terhadap lainnya, yaitu lempeng Eurasia di bagian utara yang relatif diam, lempeng Pasifik yang bergerak ke arah barat dengan kecepatan 6-10 cm pertahun (Massinai, 2013).

Pulau Buton terkenal dengan kekayaan aspalnya yang melimpah dan rembesan 
minyak yang mengindikasikan bahwa daerah tersebut sangat kaya dengan hidrokarbon yang sudah matang. Panjang pulau ini sekitar $\pm 155 \mathrm{~km}$ dan lebarnya berkisar antara 15-60 km.

Pulau Buton merupakan bagian dari Anjungan Tukangbesi - Buton, yang disusun oleh kelompok batuan sedimen pinggiran benua serta batuan malihan berumur Permo - Karbon sebagai batuan alas, sedangkan Mandala Sulawesi Timur terdiri atas gabungan batuan ultramafik, mafik dan malihan.

Tektonik dan Stratigrafi Regional
Peristiwa tektonik yang terjadi antara Tukangbesi - Buton yang menyebabkan terjadinya struktur lipatan yang terdiri dari antiklin dan sinklin, serta struktur sesar yang terdiri dari sesar naik, sesar normal dan sesar geser mendatar. Umumnya struktur berarah Timurlaut - Baratdaya di Buton Selatan, kemudian berarah Utara Selatan di Buton Tengah, dan Utara Baratlaut hingga Selatan - Tenggara di Buton Utara. Peristiwa tektonik yang terjadi berulang-ulang menyebabkan batuan-batuan yang berumur lebih tua mengalami beberapa kali aktifitas struktur, sehingga batuan tua umumnya ditemukan dengan kemiringan lapisan yang relatif tajam (Sikumbang et. al, 1995).

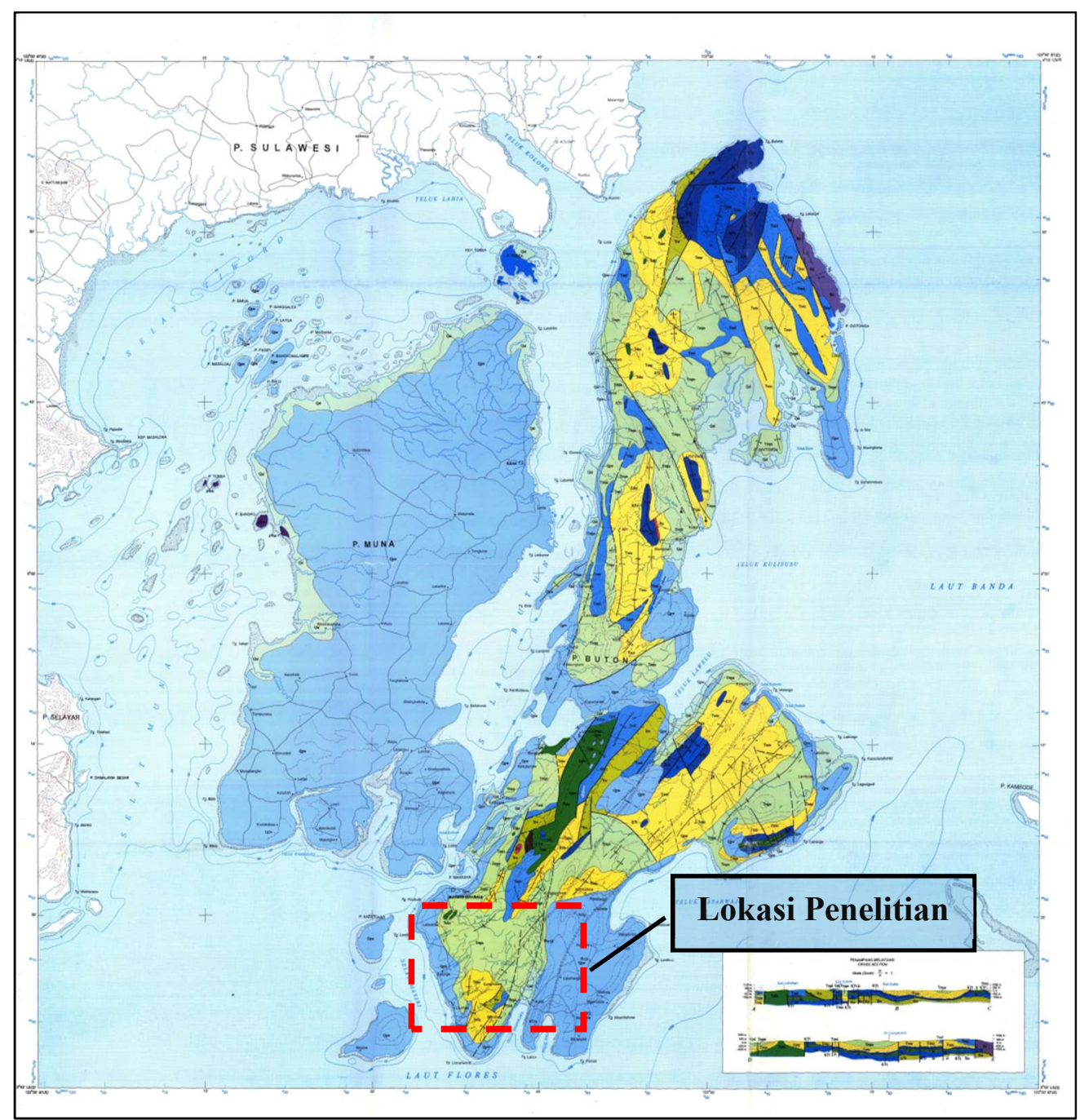

Gambar 1. Peta Geologi Lembar Buton. 
Tektonik yang terjadi di daerah Buton dimulai sejak pra-Eosen dimana pola tektoniknya sukar ditentukan disebabkan oleh seluruh batuannya telah mengalami beberapa kali perlipatan dan patahan. Gerak teknonik utama yang membentuk pola struktur hingga sekarang diperkirakan terjadi pada Eosen-Oligosen yang membentuk struktur berarah TimurlautBarat daya. Tektonik ini menyebabkan terjadinya sesar mendatar atara Buton bagian Utara dan Buton bagian Tengah sepanjang Bubu- Matewe yang diperkirakan berhubungan dengan sesar mendatar Palu-Koro. Peristiwa tektonik berikutnya terjadi antara Pliosen-Plistosen yang mengakibatkan terlipatnya batuan pra-Pliosen. Peristiwa tektonik terakhir terjadi sejak Plistosen dan masih berlangsung hingga saat ini. Tektonik ini mengakibatkan terangkatnya Pulau Buton dan Pulau Muna secara perlahan.

Daerah Buton disusun oleh kelompok batuan Mesozoikum berumur Trias hingga Kapur Atas bahkan hingga Paleosen dan kelompok batuan Kenozoikum berumur Tersier dan Kuarter. Kelompok batuan Mesozoikum terdiri atas Formasi Winto, Formasi Ogena, Formasi Rumu dan Formasi Tobelo.

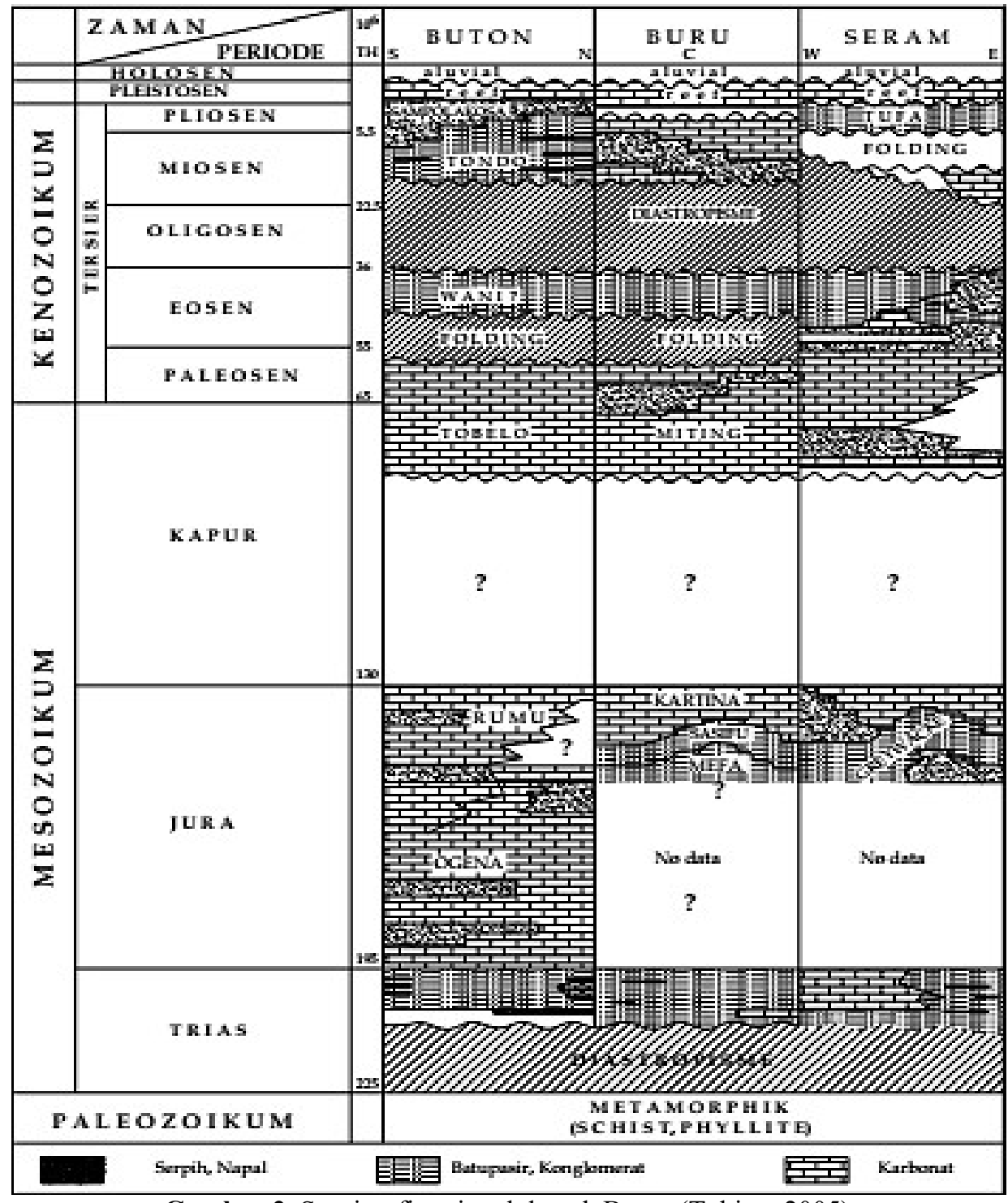

Gambar 2. Stratigrafi regional daerah Buton (Tobing, 2005). 
Kelompok batuan sedimen yang termasuk batuan Kenozoikum kemudian menutupi sebagian besar P. Buton yang terdiri atas Fomasi Tondo, Formasi Sampolakosa dan Formasi Wafulaka yang diendapkan pada Miosen Awal hingga Pliosen Akhir Plistosen. Formasi tondo dan formasi Sampolakosa merupakan tempat endapan aspal di P.Buton. Sumber aspal yang terdapat di dalam kedua formasi tersebut diduga berasal dari Formasi Winto (Trias) dan dianggap sebagai formasi pembawa Bitumen padat (Gambar 2).

Salah satu metode yang dapat digunakan untuk menganalisis kandungan logam yaitu dengan metode $X$-Ray Fluorescence (XRF). Penggunaan metode X-Ray Fluorescence dalam penelitian ini berdasarkan pertimbangan bahwa teknik ini mempunyai limit deteksi hingga satuan part per million (ppm). Selain itu metode XRF mempunyai beberapa keuntungan diantaranya biaya relative murah, multielemental, analisisnya cepat dan hasil analisisnya bersifat kualitatif dan kuantitatif. Berdasarkan uraian tersebut, maka peneliti tertarik untuk menggunakan Metode X-Ray Fluorescence (XRF) untuk menentukan komposisi kandungan mineral logam besi $(\mathrm{Fe})$, mangan $(\mathrm{Mn})$, dan nikel (Ni) pada singkapan batuan yang terdapat di Kecamatan Lasalimu Kabupaten Buton.

\section{Metode Penelitian}

Analisis laboratorium dilakukan untuk mengetahui sifat fisik dan kimiawi batuan yang tidak bisa dilakukan secara langsung di lapangan. Untuk mengetahui sifat-sifat batuan tersebut maka dilakukan beberapa analisis laboratorium, dalam penelitian ini metode yang digunakan adalah XRF $(X$ Ray Flourescence). Data yang dihasilkan oleh alat XRF kemudian dianalisis untuk menentukan konsentrasi logam oksida pada sampel batuan yang di uji.

Data yang digunakan pada penelitian ini adalah data primer. Lokasi pengambilan sampel dilakukan langsung di beberapa titik di Pulau Buton berdasarkan dengan survei lapangan dan penentuan lokasi sebelumnya menggunakan Google earth dan Global Positioning System (GPS). Hal tersebut dilakukan untuk mengetahui lokasi sebaran sampel yang telah diambil. Penentuan lokasi pengambilan sampel berdasarkan jarak, jarak antara titik sampel tidak sama karena mengacu pada peta geologi. Hal tersebut dilakukan agar sampel-sampel batuan yang diambil untuk diuji kandungannya mewakili keadaan di lapangan.
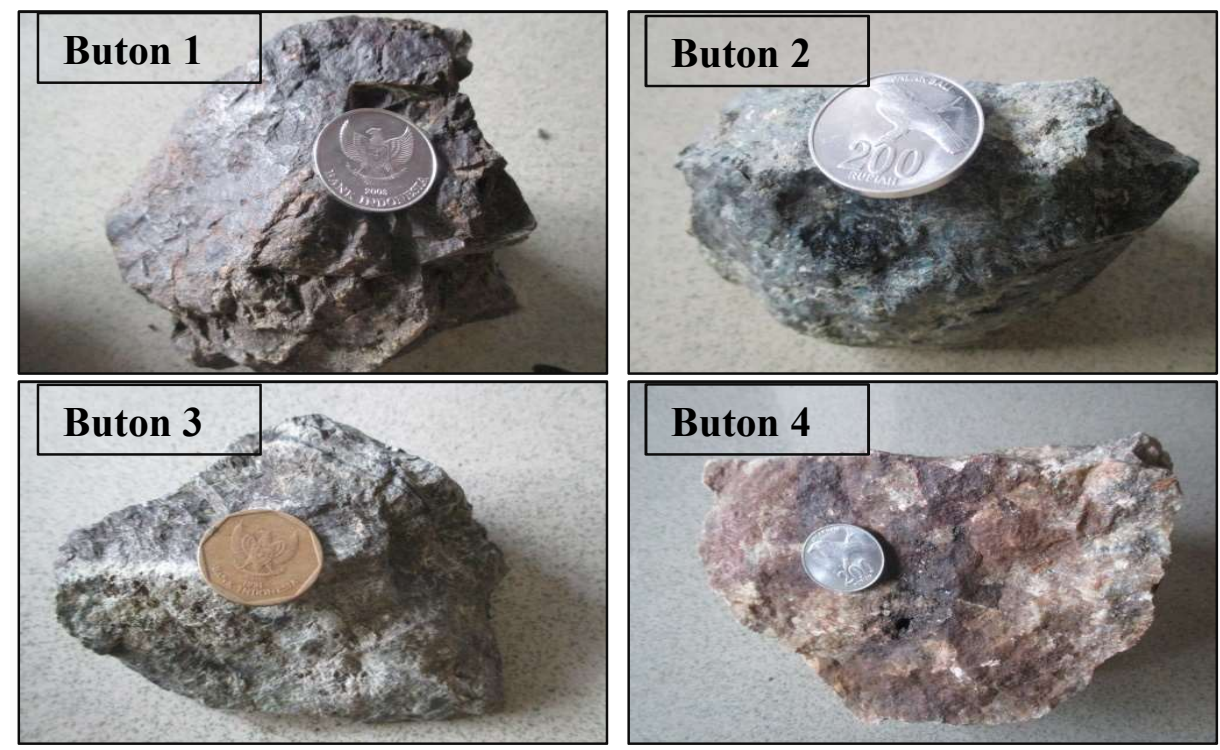

Gambar 3. Sampel penelitian 


\section{Hasil dan Pembahasan}

Kandungan logam-logam tersebut juga dipengaruhi oleh Struktur geologi. Struktur geologi yang penting adalah rekahan (Joint) dan patahan (Fault). Adanya rekahan dan patahan ini akan mempengaruhi dan mempermudah rembesan air kedalam tanah dan akan mempercepat proses pelapukan terhadap batuan induk. Selain itu, rekahan dan patahan akan dapat pula berfungsi sebagai tempat pengendapan larutan-larutan yang mengandung logam $\mathrm{Fe}, \mathrm{Ni}$, dan $\mathrm{Mn}$.
Selain itu juga dipengaruhi oleh Topografi: secara teoritis daerah yang baik untuk tempat pengendapan bijih logam adalah punggung bukit yang landai dengan kemiringan antara $10-300 \%$ dimana pada tempat ini pelapukan secara mekanis dan kimia memungkinkan terbentuknya endapan bijih logam pada batuan ultrabasa. Pada daerah yang curam, air hujan yang jatuh kepermukaan lebih banyak mengalir dari pada yang meresap kedalam tanah, sehingga yang terjadi adalah erosi intensif, unsur-unsurnya ikut tererosi (Alam, 2011).

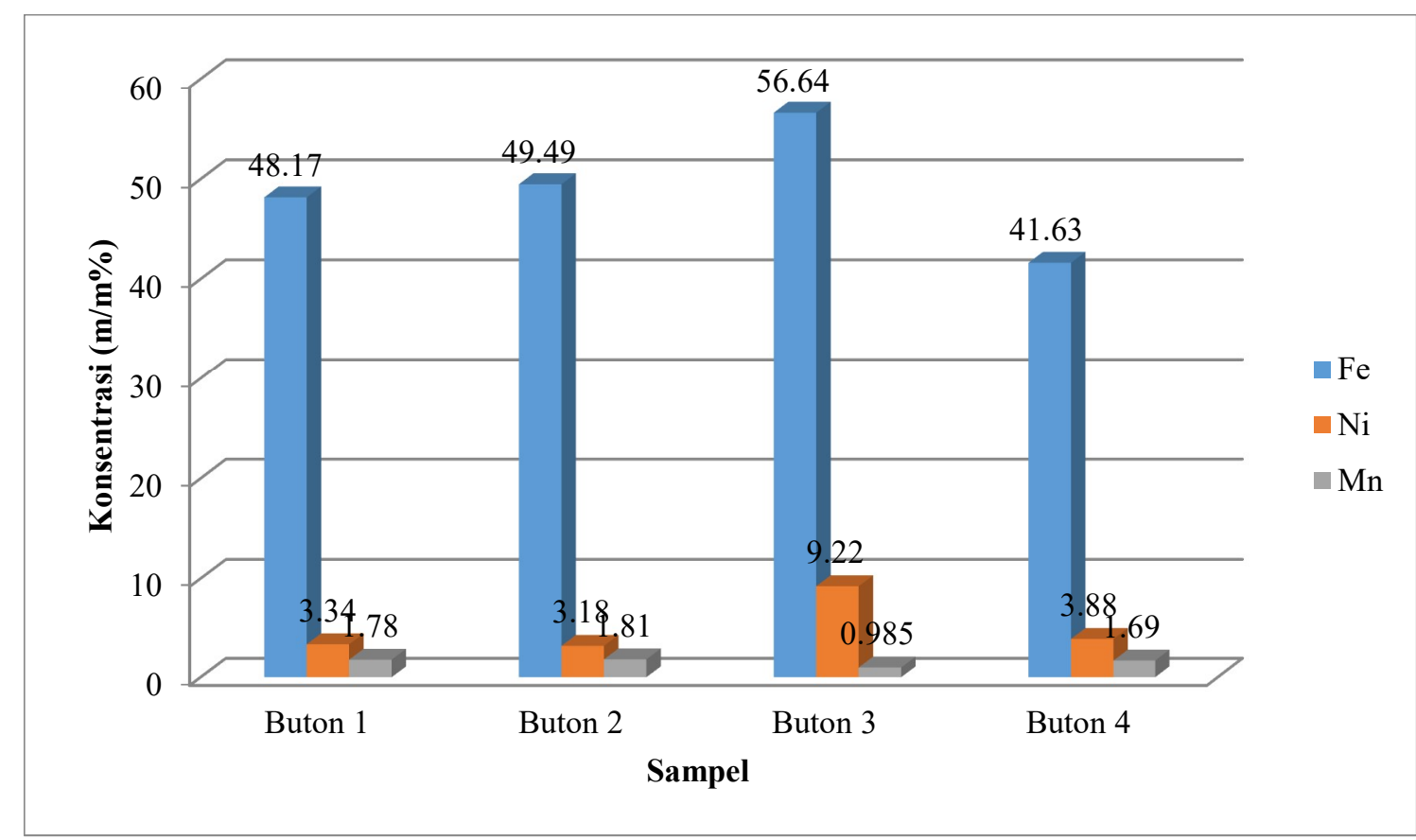

Gambar 3. Diagram konsentrasi (\%) unsur Mn, Fe, dan Ni menggunakan X-Ray Fluorescence (XRF)

Oleh karena itu kandungan mineral pada tiga titik pengambilan sampel dalam penelitian ini juga memiliki kandungan logam yang berbeda.

Hasil analisis X-ray Fluorescence (XRF) dapat dilihat berdasarkan grafik yang ada pada gambar 3 yang mengidentifikasikan jenis unsur yang terdeteksi oleh sinar $\mathrm{X}$ berupa unsur Fe , Mn , dan Ni dengan nilai konsentrasi yang bervariasi dalam bentuk bilangan perseratus (\%) dari sampel yang di uji dari ke empat sampel yang diteliti. kadar unsur logam yang paling dominan adalah besi $(\mathrm{Fe})$ yang rata-ratanya secara berturut-turut $48.17 \%, 49.49 \%, 56.64$ dan $41.63 \%$. Hal ini disebabkan karena unsur besi dominan kelimpahannya di alam dibandingkan dengan logam lain termasuk dalam batuan.

Hubungan keterdapatan unsur $\mathrm{Fe}, \mathrm{Ni}$, dan Mn berdasarkan hasil grafik menunjukan bahwa unsur $\mathrm{Mn}, \mathrm{Co}$, dan Ni berasosiasi terhadap keterdapatan endapan mineral Mangan (Mn), sementara unsur $\mathrm{Fe}$ berkorelasi negatif terhadap keterdapatan mineral Mn pada sampel. Keterdapatan mineral Mn dilokasi penelitian membentuk jalur rekahan dengan konsentrasi Mn yang 
tinggi. Diduga bahwa bijih mangan dilokasi penelitian terbentuk melalui proses sedimentasi karena adanya pelapukan dari batuan induk maka bulirbulir mineral Mn mungkin menjadi lebih stabil atau justru terlarut oleh gaya pengangkut kemudian diendapkan di tempat lain sebagai endapan sedimenter.

Tingginya kuantitas mangan dilokasi penelitian selain memberikan manfaat yang positif juga memberikan dampak yang negatif. Hal serupa yang dilaporkan (Ansori, 2010) bahwa mangan merupakan kelompok logam berat dan memiliki berat jenis $7.4 \mathrm{~g} / \mathrm{cm}^{3}$ serta tidak dapat terdegradasi atau hancur sehingga logam mangan tetap persisten ada dilingkungan. Kondisi ini memberikan informasi apabila unsur mangan terlarut dalam permukaan tanah kemudian tererosi masuk ke dalam air maka akan menyebabkan air terkontaminasi dengan logam berat sehingga akan mencemari lingkungan air.

Dari segi geologi ekonomi terdapat beberapa bahan galian yang antara lain aspal terdapat didalam formasi Sampulakosa, dan Wapulaka. Tanda adanya minyak dijumpai di daerah ini. Mangan ditemukan di dalam Formasi Rumu di daerah hulu dan sungai Rumu. Bahan bangunan seperti batugamping kerakal dan pasir.

\section{Kesimpulan}

Kabupaten Buton kaya dan beragam akan potensi bahan galian terutama aspal alam yang sudah lama diusahakan, selain bahan galian lain yang sedang diusahakan penambangannya yaitu mangan $(\mathrm{Mn})$, nikel (Ni), dan batugamping.

Berdasarkan hasil penelitian disimpulkan bahwa konsentrasi unsur logam yang dominan dari 4 sampel batuan yang diteliti adalah mineral logam besi (Fe). Hal ini disebabkan karena unsur besi dominan kelimpahannya di alam dibandingkan dengan logam lain termasuk dalam batuan.

\section{Daftar Pustaka}

Alam, A.F, (2011), Analisis Perubahan Kadar Nikel Saprolit dari Kegiatan Eksplorasi Sampai Kegiatan Penambangan pada PT. Gane Permai Sentosa (GPS) Kecamatan Obi Utara Kabupaten Halmahera Selatan Propinsi Maluku Utara, Skripsi S-1, http://wikipedia.Com,12 Oktober 2013. Ansori, C, (2010). Potensi dan Genesis Mangan Di Kawasan Kars Gombong Selatan Berdasarkan Penelitian Geologi Lapangan, Analisis Data Induksi Polarisasi dan Kimia Mineral,Buletin Sumber Daya Geologi, Volume 5.

Massinai, Muhammad Altin, Saiful Damphelas. (2013). Inventarisasi Zona Mineralisasi, Panasbumi dan Batubara di Kabupaten Donggala Sulawesi Tengah, Laporan Akhir Pemetaan Geologi Dan Inventarisasi Sumber Daya Mineral Dan Batubara Sikumbang, N., Sanyoto, P., Supandjono, R. J. B. dan Gafoer, S., (1995). Peta Geologi Lembar Buton, Sulawesi Tenggara skala 1 : 250.000. Pusat Penelitian Dan Pengembangan Geologi.Perwilayah Kecamatan.

Tobing, S. M., (2005), Inventarisasi Bitumen Padat di Daerah Sampolawa, Kabupaten Buton, Propinsi Sulawei Tenggara. Hasilhasil Kegiatan Inventarisasi Bitumen Padat dan Gambut Tahun 2005. Dept. Energi dan Sumber Daya Mineral. 